\title{
Field testing two innovative lighting interventions to influence waiting behaviours and movements on stairways in train stations
}

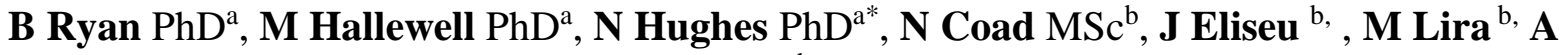 \\ Grant $^{\mathrm{c}}$, N Parrott $\mathrm{HNC}^{\mathrm{c}}$, K Thompson MEng ${ }^{\mathrm{d}}$ \\ ${ }^{a}$ Human Factors Research Group, Faculty of Engineering, University of Nottingham, UK \\ ${ }^{\mathrm{b}}$ Urban Control Ltd, , Hertfordshire, UK \\ ${ }^{\mathrm{c}}$ DW Windsor, Hertfordshire, UK \\ ${ }^{\mathrm{d}}$ Rail Safety and Standards Board, London UK
}

Short Title: Lighting interventions in train stations

Features of lighting that can influence people's behaviours have been identified in an earlier study, along with six scenarios where these could be applied to solve problems with movements through railway stations. The current paper describes the development and testing of novel lighting interventions for three of these scenarios, with two new products controlled by the Internet of Things technology integrated with operational railway systems. The first uses projected light to indicate preferred platform waiting locations. The second uses chasing LED lighting along a staircase to encourage bi-directional movements. The field study has been carried out in real-world operational railway settings. An evaluation has been based on a theory-based approach to consider whether the lighting functions as intended and whether people react in anticipated ways. The study found that the lighting interventions have been successfully implemented, and there are indications of favourable responses from passengers, though these have been small effects. The approach to evaluation also assists with diagnosis of weaknesses in the initial concepts and determination of the situational factors that can compete with the behaviour influencing effect of the lighting. This enables refinement and further product development. Practical challenges in implementing trials in this type of operational setting have been identified.

Corresponding author: Brendan Ryan, Human Factors Research Group, Faculty of Engineering, University Park, University of Nottingham, NG7 2RD. brendan.ryan@nottingham.ac.uk

\section{ORCID ID}

Brendan Ryan ORCID ID - 0000-0002-8629-9634

Nancy Hughes ORCID ID - 0000-0003-1567-7623

Madeleine Hallewell ORCID ID - 0000-0002-2710-2176 


\section{Introduction}

The rail industry faces many challenges in enabling effective movements of people, with differing levels of rail travel experience (e.g., commuters vs leisure travellers ${ }^{1}$ ) through railway stations with different layouts, features and conditions. ${ }^{2}$ Signage is a common approach to support wayfinding at stations, ${ }^{3}$ though with a plethora of information requirements (e.g., platforms numbers, train destinations, facilities, safety messaging, advertising) stations are commonly cluttered with too much visual information. ${ }^{4}$ Hughes et al. $(2020)^{5}$ presented arguments for how different characteristics of lighting (intensity, colour, flicker/flash rate, position/direction, source/operation) could be used to influence the behaviour and movements of people in a more intuitive and responsive way at railway stations, with the potential to solve recognised industry problems with passenger movements and their impacts on efficiency of train services. ${ }^{6}$

Six scenarios were identified where new lighting interventions could be considered. ${ }^{5}$ The efficacy of these types of lighting interventions, proposed following analysis of the literature, is not known. Traditional experimental approaches are difficult to implement in environments such as a live railway station, ${ }^{7}$ so it was necessary to develop a rigorous evaluation methodology that can be applied in this type of operational context. Existing frameworks for evaluation of transport/rail safety interventions are available, especially the theory-based, realistic evaluation ${ }^{8-10}$ or logic mapping ${ }^{11}$ approaches. These focus on the concept or theory behind the intervention, contain an explicit description of the intervention, how it is implemented, the context in which it is being implemented and a range of potential indicators of the outcome and impact of the intervention. The intention is to answer questions such as whether, how and why an intervention works. ${ }^{8}$ An advantage of this type of approach is that it enables the research and development team to see more clearly the strengths and weaknesses in what they are trying to achieve with the intervention, drawing upon a range of different data types.

Therefore, the current study aims to explore how passengers respond to two new lighting interventions when these are implemented within the setting of a railway station. This is an exploratory evaluation study and is important as there are no similar examples of realworld studies of this kind, with other such tests typically carried out in simulated environments. ${ }^{12-14}$ The intention was to study the feasibility of these new lighting interventions and establish the methodology that can be used in future studies. In doing so, it was important that researchers were prepared to be flexible and accept compromises ${ }^{15}$ in the collection of data in an operational railway setting, where it was difficult to have control over study variables and 
research activities (such as accessing study participants or the arrival times of trains). The study is therefore descriptive in approach, providing the grounding for future studies with control of more variables.

The selected lighting interventions correspond with three of the scenarios identified in the earlier study. ${ }^{5}$ Firstly, there are known problems of passengers not knowing where on the platform to wait for a train (Scenarios 1 and 2), ${ }^{5}$ causing blockages in flow on platforms, uncertainty for passengers and increased dwell times of trains at stations. An overhead projected lighting product was developed to produce light zones to indicate optimal waiting positions for boarding and encourage dispersion along the length of the platform. Secondly, movements in confined spaces such as stairways and bridges (Scenario 4$)^{5}$ also contribute to blockages, delay, frustration and safety incidents (e.g., slips, trips and falls). A new handrail product containing coloured and chasing lights was developed to influence the trajectories of passengers (e.g., left / right separation) and support bi-directional movement on stairs or corridors at appropriate walking speeds.

Results from the initial field tests are presented, along with commentary on the challenges for researchers and developers in this type of evaluation study. Experience of completing this initial evaluation helps in clarifying the most important data types and methods to be applied in this context, leading to recommendations for further development and testing of these novel lighting interventions.

\section{Description of the lighting products}

\subsection{Projected lighting along the length of a platform}

The projected light provides a visual cue, aligned with the expected location of the train doors, to indicate the position for passengers to congregate prior to the arrival of the train. The product was based around a commercial light projector (Gobo - Goes Before Optics, Figure 1(a)) with a custom-built lens to produce the visual cue. The operation of the light projection was linked to the arrival of the train by software integrating with the train management system. This projection was designed to be activated approximately three minutes before the arrival of a train, with the lights flashing on and off for 10 seconds as a cue for passengers to react. The projection then remained static until the train departed. The Central Management System (CMS) software provided a user interface to configure and control the lighting via a Bluetooth Mesh Network. The CMS could also fetch train arrival information from a publicly available platform (Tiger Platform) for real-time information and integration of the lighting function with 
the features of trains (e.g. train type and numbers of carriages) arriving into the railway station. All data were logged for historical analysis.
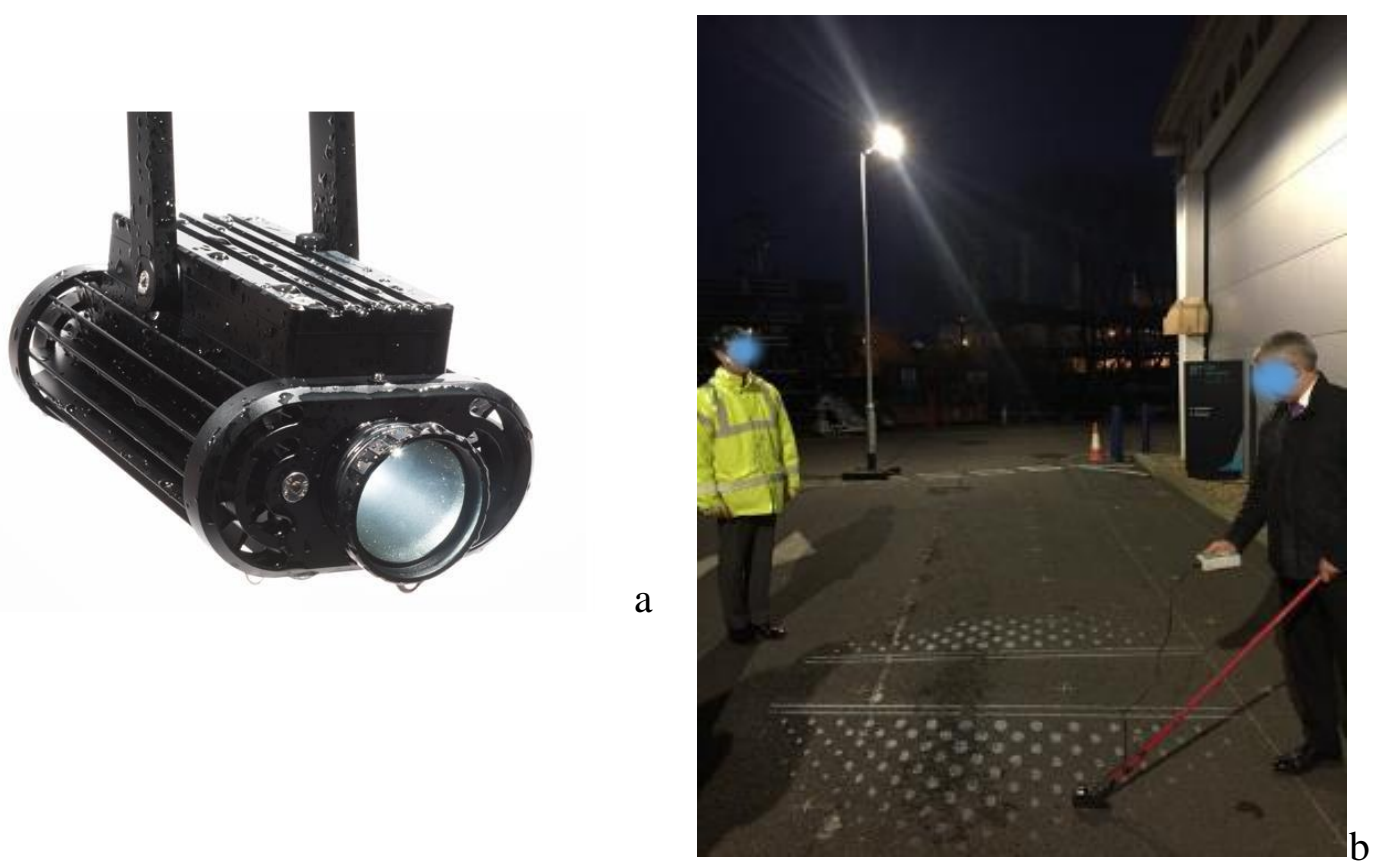

Figure 1. (a) Image of the commercial projectors to be used at intervals along the platform, (b) Early designs for the projected image.

The projection image was designed to display a simple visual cue to indicate the target waiting location (similar to a spotlight in stage setting). An early prototype of the image is shown in Figure 1(b), though this was adapted in a later stage of development to fit with operational requirements at the site (the final version of the image is shown later in Figure 3). Several factors were considered in the development of the projected image, such as luminance, uniformity, image distortion due to the location of the projector, and the intensity of the light, given that it would compete with natural daylight.

To support distribution of passengers along the platform, seven projectors linked to the CMS were fitted at intervals under the station canopy, aligned with desirable waiting areas for the doors of a 10 carriage intercity train.

\subsection{Handrail lighting on a stairway}

A stairway lighting product was designed to provide visual cues for the desired paths when ascending and descending, to encourage bi-directional flow and improve the safety and 
efficiency of passenger flows on the stairway. This was achieved by using white and blue chasing lights embedded within a handrail to indicate preferred movement directions. Figure 2 shows how this new handrail was installed in between two existing handrails, along each side of the stairway.

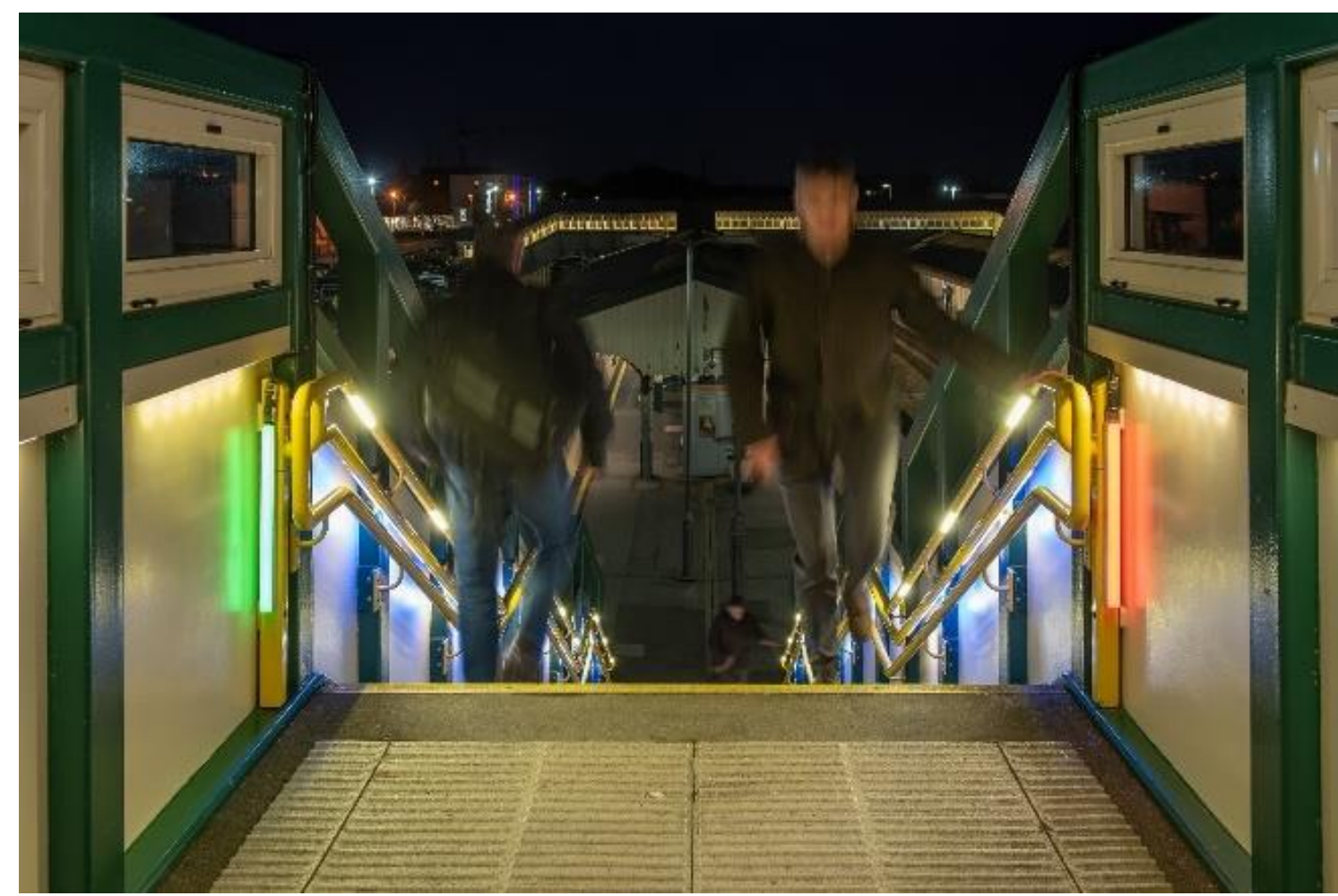

Figure 2. View from the top of the staircase of the final product.

The blue lights flow downwards on the left side of the stairway (when viewed from the top) and upwards on the right. This lighting product was linked to the CMS, with the ability to change features such as colour, level of illumination and speed of the chasing movement of the lights. These could, in principle, be varied in response to changes in passenger numbers on the stairway. In this study, these were tested at a fixed colour and speed of $1.3 \mathrm{~km} / \mathrm{hr}$, assumed to support a safe speed of movement. In addition, a red and green lighting product was located at the top entrance to the stairs on either side (Figure 2) as an additional cue to convey information on the preferred side of entry to the staircase for those descending. It was not possible to provide a green/red lighting cue at the bottom (platform end) of the staircase because of the potential risk of distraction for train drivers (more information about safety analyses is provided in Section 3.2). 


\section{Method for evaluation of the lighting interventions}

\subsection{General approach to the evaluation study}

The evaluation was built around a simplified approach to logic mapping. ${ }^{11}$ The original guidance $^{11}$ focuses on considering the context of the intervention and mapping the intervention logic from the inputs (what has been invested), outputs (what has been produced), outcomes (short and medium term results), through to the impacts (overall goal, often realised over long periods of time and termed long term impacts in this study). The use of a logic map in the current study was to broaden the focus on how the interventions have been implemented and on the different types of data that can be considered in determining whether and in what ways this has been effective. Simplified logic maps were prepared, as shown in Table 1.

An overall aim of the platform lighting is to improve the efficiency of boarding/alighting trains, such as by reducing train dwell time, slips, trips and falls and also improving passenger experience. These are desirable within the rail industry and essential in the future development of lighting interventions. However, it is not easy to determine these in short term tests due to the many factors that can influence how long a train may be at a station platform. Such changes may only be observable in the long term over many observations. However, there is much that can be achieved within a well-designed trial, and important data types on the pathway to achieving the desirable impacts of the lighting can be identified. An objective of the current study was to clarify the types of data that could be used in evaluating passenger responses to the lighting. The logic map shows pathways from the input (successful implementation of the intervention) through to the long term impacts. For the field work in the current study, the evaluation focused on three aspects from the logic map, as highlighted in bold in Table 1.

In this early phase of development, it is important to fully appreciate whether the lighting is working in the operational context in the way that it was intended at the design stage. This is not just from a technical or functional perspective, but needs consideration of whether the working product, in situ, provides the type of cue that was originally intended. Assuming that this is working as intended, it is then necessary to determine how people respond to the lighting. A part of this evaluation was based on the passengers' experiences of the lighting. Other types of data could be collected as part of a comprehensive evaluation, assuming the availability of technical equipment and more time and resources for the evaluation. These are retained within the logic maps in Table 1, as they show the pathways to demonstrating the long term goal (e.g., reducing dwell time at the station platform) and are an important part of the comprehensive methodology that is being developed. 
Table 1. Logic map for the projected lighting and stairway lighting (items in bold provide a focus for data collection in the current study)

\begin{tabular}{|c|c|c|c|c|}
\hline $\begin{array}{l}\text { Lighting } \\
\text { type }\end{array}$ & Inputs & $\begin{array}{l}\text { Short term } \\
\text { outcomes }\end{array}$ & $\begin{array}{l}\text { Medium term } \\
\text { outcomes }\end{array}$ & Long term impacts \\
\hline \multirow[t]{5}{*}{$\begin{array}{l}\text { Projected } \\
\text { lighting }\end{array}$} & $\begin{array}{l}\text { The lighting } \\
\text { intervention is } \\
\text { functioning as } \\
\text { intended (timing, } \\
\text { position) }\end{array}$ & $\begin{array}{l}\text { Passengers respond } \\
\text { to the lighting } \\
\text { /move to stand (for } \\
\text { their carriage / } \\
\text { door) }\end{array}$ & $\begin{array}{l}\text { Reduction in boarding } \\
\text { times }\end{array}$ & $\begin{array}{l}\text { Reduction in general } \\
\text { 'dwell time' (and } \\
\text { incurred costs) }\end{array}$ \\
\hline & & $\begin{array}{l}\text { Passengers distribute } \\
\text { evenly along a } \\
\text { platform }\end{array}$ & More orderly boarding & $\begin{array}{l}\text { Reduction in } \\
\text { slips/trips/falls } \\
\text { (boarding \& } \\
\text { alighting) }\end{array}$ \\
\hline & & & $\begin{array}{l}\text { Passengers } \\
\text { appreciate the } \\
\text { lighting } \\
\text { intervention(s) }\end{array}$ & $\begin{array}{l}\text { Improvements in } \\
\text { passenger } \\
\text { experience }\end{array}$ \\
\hline & & $\begin{array}{l}\text { Passengers' exit } \\
\text { from the train is clear }\end{array}$ & $\begin{array}{l}\text { Reduction in alighting } \\
\text { times }\end{array}$ & \\
\hline & & $\begin{array}{l}\text { Passengers respond } \\
\text { to the lighting / know } \\
\text { where to go (which } \\
\text { route to take) }\end{array}$ & More orderly alighting & \\
\hline \multirow[t]{4}{*}{$\begin{array}{l}\text { Stairway } \\
\text { lighting }\end{array}$} & $\begin{array}{l}\text { The lighting } \\
\text { intervention is } \\
\text { functioning as } \\
\text { intended (speed/ }\end{array}$ & $\begin{array}{l}\text { Passengers move } \\
\text { up/down on the } \\
\text { appropriate side of } \\
\text { the stairway }\end{array}$ & $\begin{array}{l}\text { More orderly } \\
\text { movement on the } \\
\text { stairway }\end{array}$ & $\begin{array}{l}\text { Improved safety and } \\
\text { reduction of } \\
\text { slips/trips/falls on } \\
\text { the stairway }\end{array}$ \\
\hline & & $\begin{array}{l}\text { Passengers move at } \\
\text { an appropriate speed }\end{array}$ & $\begin{array}{l}\text { Passengers } \\
\text { appreciate the } \\
\text { lighting } \\
\text { intervention(s) }\end{array}$ & $\begin{array}{l}\text { Improvements in } \\
\text { passenger } \\
\text { experience }\end{array}$ \\
\hline & $\begin{array}{l}\text { The lighting } \\
\text { intervention can } \\
\text { be seen clearly by } \\
\text { those entering the } \\
\text { stairway }\end{array}$ & $\begin{array}{l}\text { Passengers' entry to } \\
\text { the stairway is clear }\end{array}$ & $\begin{array}{l}\text { Passengers move } \\
\text { more freely/safely on } \\
\text { the stairs }\end{array}$ & $\begin{array}{l}\text { Regular passengers } \\
\text { automatically use } \\
\text { the stairway in the } \\
\text { preferred manner }\end{array}$ \\
\hline & & & $\begin{array}{l}\text { Stairway clears more } \\
\text { quickly during busy } \\
\text { times }\end{array}$ & \\
\hline
\end{tabular}

Multiple methods were used to collect data in periods before and after the introduction of the lighting interventions at the platform area and a stairway at the station. These were largely based around field observations, though also included a questionnaire survey with passengers and interviews with staff. These are explained in detail for each of these methods within Section 3.2 to 3.7. The evaluation of the interventions in this field study was carried out using challenging conditions that explored whether the lighting would provide intuitive 
behavioural cues to passengers. No overt explanations of the purpose of the lighting were provided to passengers, and the research methods were designed with care so as not to influence the respondents (e.g., survey participants were not prompted initially about the lighting and broader questions were used first to determine whether people would freely report on the new lighting features and their experiences of interacting with these).

\subsection{Study location}

Access to operational environments for testing purposes is difficult to achieve, particularly within the safety-critical railway environment. Visits were carried out at a selection of railway stations to determine site-specific details that could impact upon the successful installation and subsequent use of the novel lighting. The final choice of the station was constrained by the need to complete this study at a location with low safety risk. The chosen location was a small station in the Southwest of England, on a mainline to London. Whilst there were reasons why this was not ideal for exhaustive testing of the products, the opportunity to implement the study in a real-world station setting was important, both to support the on-going development of the products and to evaluate the methods used in the field studies. Important steps in preparing for the field study included developing a thorough understanding of local features, such as the configuration of the platforms and stairways, typical passenger numbers and flows through the station, timings of trains and stopping patterns, and tolerances in stopping positions. It was also important to obtain relevant permissions for safety assessment. This included HAZOP assessment, ${ }^{16}$ an established hazard and operability method, to assess safety for those involved in the fitting of products near to the live railway and those who might be impacted by the operation of the products (e.g., train drivers, passengers). A privacy/data protection agreement was completed, detailing the responsibilities of each partner to ensure best practice relating to the collection, storage, retention and disposal of related data. Ethical approval for the study was granted according to processes at the University of Nottingham. Planning and architectural considerations were discussed with local planning and station owners regarding fitting and removal of lighting equipment without damaging the fabric of the buildings in a location that had protection for reasons of heritage.

\subsection{Study materials}

Table 2 provides summary details of the content of the different checklists, questionnaires and interview protocols for the platform study and the stairway study. Researchers carried out direct observations before and after implementation of the lighting, guided by observer 
checklists for the projected lighting and stairway studies (Table 2). Detailed outlines of these checklists are available in Table A1 in the Supplementary Material. For the projected lighting study, the observation checklist was used to note passenger numbers, positions and behaviours in the platform area, recording details in a plan view diagram. For the stairway lighting study, the checklist was used to record movement pathways and descriptions of observable movements of people on the stairway in periods when the lighting was and was not operational. A fixed video camera installed above the regular location of one train door captured passenger locations and behaviours in the vicinity of the light projection on the ground (Figures 3(a) and 3(b)). The observation checklist (also outlined in Table 2, with more details in Table S1 in the Supplementary Material) was used to extract data from the videos, notably assessment of the alignment of the lighting with the train doors, counts of passengers in the area of view of the camera, and responses of passengers to the lights.

Questionnaires were used to collect initial feedback from passengers about their behaviours and movements around the train station and their opinions on the lighting on the platform and stairway areas (Table 2, with more details of the questions in Table S2, Supplementary Material).

Interviews were conducted with station staff to collect their accounts of passengers' movements around the train station platform and stairway, using a protocol of questions (Table 2 , with more details of the questions in Table S3, Supplementary Material), including questions on whether people know where to stand, problems with crowding, use of the stairway and boarding trains, and opinions on the lighting. 
Table 2. Summary of data collection for the platform and stairway lighting studies

\begin{tabular}{|c|c|c|c|c|}
\hline \multirow[b]{2}{*}{ Method } & \multicolumn{2}{|c|}{ Station platform } & \multicolumn{2}{|c|}{ Stairway } \\
\hline & Pre-intervention & Post-intervention & Pre-intervention & Post-intervention \\
\hline Observation & $\begin{array}{l}\text { Timings of train arrivals and departures } \\
\text { Annotated diagram of locations of } \\
\text { people at different times leading up to } \\
\text { the expected arrival of the train } \\
\text { Descriptions of observable aspects of } \\
\text { behaviour (e.g. movement into and out } \\
\text { of the area, timing of movement toward } \\
\text { the yellow safety line) }\end{array}$ & $\begin{array}{l}\text { As pre-intervention, plus } \\
\text { Timings of operation of lights and door } \\
\text { opening / closing times } \\
\text { Descriptions of visibility, functioning, } \\
\text { synchronisation of lights. } \\
\text { Assessment of alignment with the train } \\
\text { Counts of passengers in the area of view } \\
\text { of the camera } \\
\text { Observable responses of passengers to } \\
\text { the lights (e.g. looking, movement in } \\
\text { response) }\end{array}$ & $\begin{array}{l}\text { Timings of train arrivals and departures } \\
\text { Recording of movement pathways on a } \\
\text { grid } \\
\text { Descriptions of observable movements } \\
\text { of people on the stairway at } 1 \text { minute } \\
\text { intervals before the published train } \\
\text { time } \\
\text { Behaviours relating to safety (e.g. use } \\
\text { of handrail, carrying luggage, running) }\end{array}$ & $\begin{array}{l}\text { As pre-intervention, plus } \\
\text { Lighting operation (speed of lighting } \\
\text { movement and visibility of direction of } \\
\text { flow) } \\
\text { Observable responses to the lighting (e.g. } \\
\text { looking, touching) }\end{array}$ \\
\hline Questionnaire & $\begin{array}{l}\text { Frequency of station use } \\
\text { Typical waiting time at the station } \\
\text { Typical location to wait for the train } \\
\text { Three factors that influence waiting } \\
\text { location } \\
\text { Typical passenger response to prepare } \\
\text { for boarding as the train arrives } \\
\text { Previous/common issues with boarding } \\
\text { or alighting } \\
\text { Satisfaction with experience of } \\
\text { boarding or alighting } \\
\text { Age and gender }\end{array}$ & $\begin{array}{l}\text { As pre-intervention, plus } \\
\text { Whether the new lighting has been } \\
\text { observed } \\
\text { Perceived purpose of the lighting } \\
\text { Visibility of the lighting } \\
\text { Helpfulness of the lighting for boarding } \\
\text { and alighting } \\
\text { General feelings about the lighting }\end{array}$ & $\begin{array}{l}\text { Previous/common issues ascending and } \\
\text { descending } \\
\text { Satisfaction with experience of use of } \\
\text { the stairs } \\
\text { Age and gender }\end{array}$ & $\begin{array}{l}\text { As pre-intervention, plus } \\
\text { Awareness of new lighting on the } \\
\text { handrails } \\
\text { Perceived purpose of the lighting } \\
\text { Visibility of the lighting } \\
\text { Helpfulness of the lighting } \\
\text { Effectiveness in guiding speed of } \\
\text { movement } \\
\text { Overall feelings about the lighting } \\
\text { Other comments }\end{array}$ \\
\hline Interview & $\begin{array}{l}\text { Staff perceptions on whether people } \\
\text { know where to stand. } \\
\text { Problems of crowding on the platform } \\
\text { What the staff do to prevent crowding } \\
\text { Whether people stand in the best } \\
\text { position for boarding and alighting } \\
\text { Experience of problems with boarding } \\
\text { and alighting } \\
\text { What the staff do to prevent problems } \\
\text { with boarding and alighting }\end{array}$ & $\begin{array}{l}\text { As pre-intervention, plus } \\
\text { Overall impressions of the lighting } \\
\text { Whether the lights worked correctly } \\
\text { Significant observable passenger } \\
\text { reactions to the lighting } \\
\text { Passenger feedback on the lighting (e.g. } \\
\text { complaints, questions) } \\
\text { Whether the lights are useful }\end{array}$ & $\begin{array}{l}\text { Experience of problems related to } \\
\text { movements on staircases } \\
\text { What staff do to prevent problems with } \\
\text { movements of staircases }\end{array}$ & $\begin{array}{l}\text { As pre-intervention, plus } \\
\text { Whether the lights worked correctly } \\
\text { Significant passenger reactions (e.g. } \\
\text { movement in response to the light) } \\
\text { Passenger feedback on the lighting (e.g. } \\
\text { comments, complaints) } \\
\text { Whether they feel the lights could } \\
\text { achieve their stated purpose }\end{array}$ \\
\hline
\end{tabular}



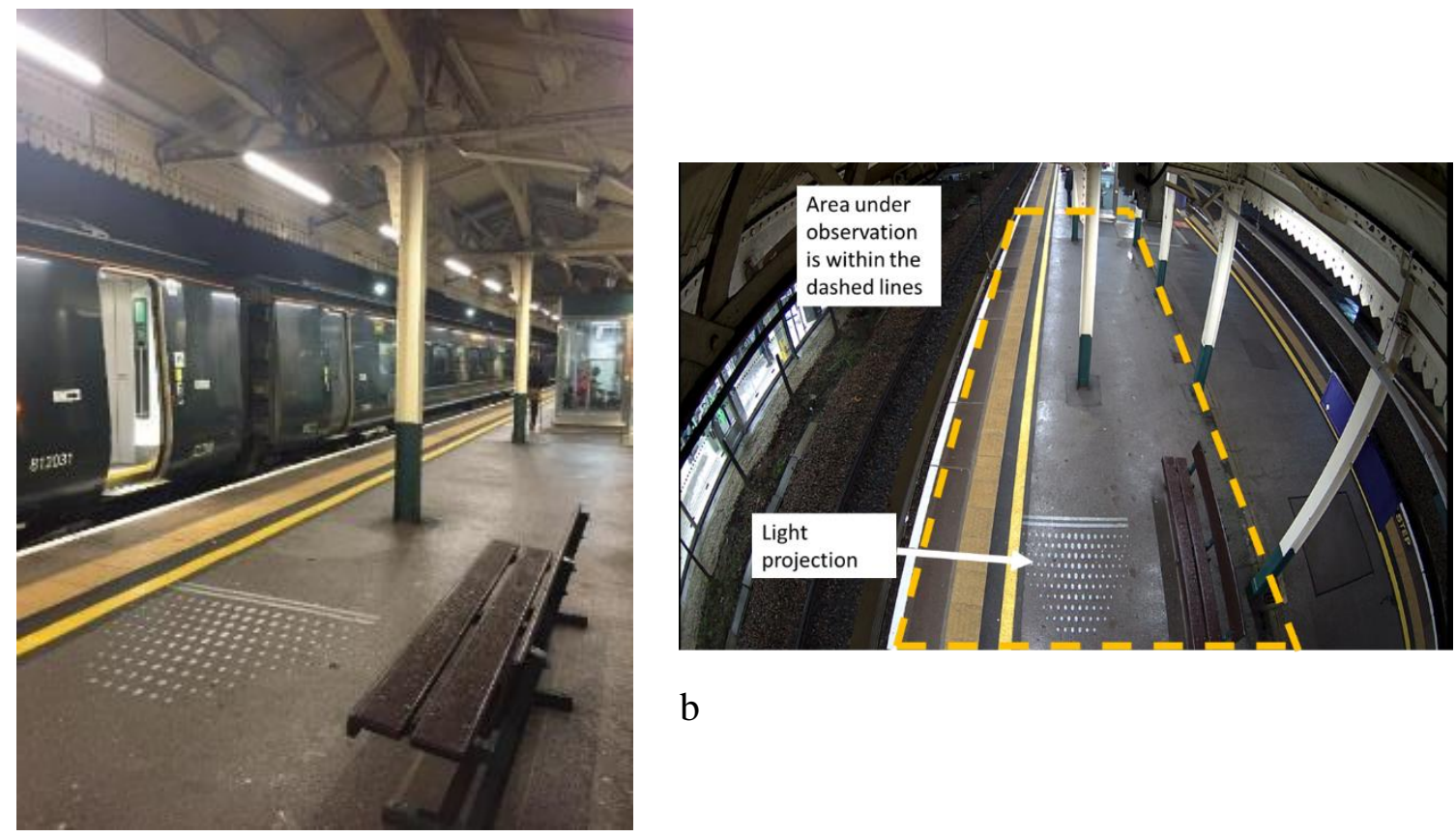

$\mathrm{b}$

a

Figure 3. (a) Typical view of the platform and awaiting a train; (b). View from the fixed, overhead camera.

\subsection{Participants}

Participants for the study's observational parts were the passengers who were in the observed areas (explained in section 3.5). For the completion of questionnaires, passengers waiting on the platform, or those observed descending the stairway, were approached as potential participants for paper-based or online surveys, to collect a small convenience sample of passengers' opinions. There are no data for the numbers of passengers who were approached and declined to take part in the survey, and it is not possible to determine a response rate for the online survey. Twenty-four participants completed the survey (13 prior to the intervention and 11 post-intervention). The participants were distributed across age groups from 18-24 through to $75+$, with a slightly higher proportion of male respondents (13 male : 9 female) and most visited the station at least a few times each month (22 out of 24). Six staff members from this location took part in the interviews ( 4 before the intervention and 2 after the introduction of the lighting). There were regularly three to four eligible staff members (i.e., operational/dispatch) working at this location during the research visits, and all who were working in the dispatch office at the time of station visits were invited to participate. 


\subsection{Procedure for the study of projected lighting along a platform}

The observations, interviews and questionnaire surveys were carried out at a single platform in periods before and after implementing the projected lighting intervention between October 2019 and January 2020. Data were collected in relation to passenger movements associated with 20 intercity (10 carriage) commuter trains stopping at the study platform over a two day period. In consultation with operational rail industry staff, the times of trains in the peak periods were identified, where crowding was likely to be greater (morning and early evening). At the selected platform, crowds of people waiting for the morning trains tended to build up before 9:30 am, and crowds returning from London would exit the train and move through the station during the late afternoon/early evening period. For this exploratory study, observations were also carried out for a smaller sample of the two trains around the mid-day period, where rail staff indicated that passenger numbers would rise a little.

Direct observations by a researcher were carried out from 10 minutes prior to the departure time of a timetabled train to the point when the train departed, enabling approximately 8 minutes to observe passengers on the platform and approximately 2 minutes of alighting / boarding. Figure 3(a) shows a typical view at the location. The observation checklist was used to record passenger numbers, positions and behaviours in the area. Photographs were taken to collect details of the positioning of passengers (e.g., congregating at train doorways). The observation method was identical in both the pre and post-intervention study periods.

Footage from the fixed camera for the twenty trains in the period after the introduction of the lighting was analysed using the observation checklist (explained later in section 3.7).

Passengers were approached at off-peak times and asked to complete a 5-10 minute questionnaire (details in Table 2). In efforts to overcome the limited time available to many passengers before the arrival of their train, the administration method was adapted for the postintervention survey. Passengers were given information (including URL link and QR code) for an online version of the survey, which included additional questions relating to the new lighting. Information about the survey was also displayed at the station in posters to reach a larger sample of respondents.

Staff at the station were approached and asked to participate in a 15-20 minute interview regarding the behaviours of passengers on the study platform. 


\subsection{Procedure for the study of handrail lighting on the stairway}

Investigating movement pathways of people on the staircase was achieved through real-time observations. It was not possible to install a fixed video camera at this open staircase. There is no general consensus within the literature whether people naturally use the left or right side of stairways, because the choice can depend on a number of factors (such as the staircase configuration and entry / exit points, presence of other people, and personal space available). ${ }^{17,18}$ Similarly, walking speeds can vary depending on length of stairway ${ }^{19}$ or level of physical exhaustion. ${ }^{20}$ Preliminary observations were carried out to determine the types of behaviours that could be observed on this staircase, such that any differences in behaviours after fitting of the lights could be considered.

The preliminary observation period collected data on passenger numbers and examined general behaviours prior to and after the departure of 15 trains, observing movements of 206 passengers. A simple approach was used to classify the movements in ascending or descending on the left, middle, or right of the staircase. There were some busier periods, typically after passengers had alighted from a train, and it was difficult at these times to discern movement pathways or individual behaviours. This initial period of observation indicated that passengers could move laterally on the staircase, in addition to ascending or descending. Data from these initial observations are treated as a pilot informing further development of the observation method, and findings are not reported in this paper.

The approach to observation was revised to record numbers of people and their movement pathways using a grid $^{21}$ that divided the staircase into 15 zones (i.e., three vertical sections and five horizontal sections, see Figure 4) to account for lateral movements. This was used during observations of a further five trains in the period prior to the intervention and in relation to 14 trains in the period after the introduction of the lighting. The observations began seven minutes prior to the timetabled train departure and up to five minutes following the train's departure, with some variation depending on the actual arrival/departure times of the train. 


\begin{tabular}{|c|c|c|c|}
\hline & $\begin{array}{l}\text { To/from } \\
\text { lift }\end{array}$ & Middle & $\begin{array}{c}\text { To/from } \\
\text { gates }\end{array}$ \\
\hline $\begin{array}{l}\text { Entry / } \\
\text { exit }\end{array}$ & Zone 1 & Zone 2 & Zone 3 \\
\hline $\begin{array}{l}\text { Top } \\
\text { section }\end{array}$ & Zone 4 & Zone 5 & Zone 6 \\
\hline $\begin{array}{l}\text { Mid- } \\
\text { section }\end{array}$ & Zone 7 & Zone 8 & Zone 9 \\
\hline $\begin{array}{l}\text { Bottom } \\
\text { section }\end{array}$ & Zone 10 & Zone 11 & Zone 12 \\
\hline \multirow{2}{*}{$\begin{array}{l}\text { Entry / } \\
\text { exit }\end{array}$} & Zone 13 & Zone 14 & Zone 15 \\
\hline & $\begin{array}{c}\text { To/from } \\
\text { Platform } \\
1\end{array}$ & Middle & $\begin{array}{c}\text { To/from } \\
\text { platform } \\
2\end{array}$ \\
\hline
\end{tabular}

Figure 4. Template for observing movement paths on the stairway during baseline observations.

Photographs were taken at one-minute intervals if there were people on the stairway or at additional times when it was felt that a photograph would effectively illustrate aspects of behaviour. Field notes were recorded for general observations during the period.

Passengers who had descended the stairway were approached during off-peak times to participate in the questionnaire about their experience of the stairway. Members of staff were approached and asked to take part in interviews about issues associated with the stairway, also including questions about the new lighting in the post-intervention period.

\subsection{Analysis}

Analyses of the data from direct observations included a review of notes, photographs, and annotated diagrams to determine counts and locations of people in different parts of the platform, clusters of passengers, interactions, activities, and passenger movements in relation to the selected trains. Content from the fixed video camera was initially reviewed by two researchers, reaching an agreement about the behaviours of interest and recording these in a number of behaviour categories in a spreadsheet. The train's relative position in relation to the lighting and various timings (activation of the lighting, train arrival, door opening, completion of alighting from the train, completion of boarding of the train, closure of the train doors and departure) were also recorded. Activities and movements of passengers were also described, focusing on any passenger entering or passing through the area illustrated in Figure 3(b) during 
the time period one minute before the operation of the lights until five minutes after the light had been activated.

During preliminary analyses of the videos, various reactions to the lights could be observed (e.g., looking at the lights). Characteristics of these interactions with the light projection were described in short written records of the video extracts, and these descriptions were reviewed and collated to produce a preliminary descriptive classification of five observable passenger responses to the lighting (presented in Section 4.1). Timings of these interactions were noted (e.g., relative to the activation of the lights and arrival of the train), also noting whether the train was present and where passengers were standing (i.e., in relation to the light projection) and the frequencies of observable behaviours/events.

Analyses from observations of the staircase were based on the field notes and photographs from the site visits, extracting details of counts of passengers during minute intervals of time before and after the arrival of the train. The movement pathways of passengers were noted (in accordance with zones in Figure 4). These records were used in exploring how passengers were distributed on the staircase.

Responses to fixed choice questions and rating scales within the survey data were counted. The response to the survey was small, and no further statistical analyses have been attempted. Responses to open questions in the survey were extracted, and an inductive qualitative content analysis ${ }^{22}$ was conducted to classify and identify common opinions on a range of topics within the questionnaire. Interviews with staff were transcribed, and a qualitative content analysis was again used to code, extract, and collate content, though in this case using a partially directed approach to coding 22 that was influenced by content in the logic map (e.g., functioning of the lighting, passenger responses to the lighting).

Where relevant, findings from the different parts of the study were synthesised at the point of reviewing and collating findings from the different study methods, considering where these findings help to improve understanding of the responses to the lighting interventions, but also where there was complementarity or dissonance in the findings from the different data sources. ${ }^{23}$ The highlighted content from the logic maps has been used to report a synthesis of the findings from the different data sources. 


\section{Results}

\subsection{Findings from the study of projected lighting along platforms}

To determine whether the lighting intervention was functioning as intended, the video data were examined for evidence relating to the functionality of the lights. This is important to establish, as a lack of a reaction to the lighting would not be surprising if this was not functioning as intended. Checks of functionality included consideration of the time that the lights activated and deactivated and the visibility of the lights. Generally, the lights functioned as intended, appearing approximately three minutes before the arrival of the train (flashing for an initial 10 seconds) and remaining until the train departed. However, there were a few issues that arose. For example, the lights were most visible during the hours of darkness, as indicated in Figure 5 below. Issues associated with interpretation of the lighting cue are covered later in this section.

\begin{tabular}{|l|l|l|l|l|}
\hline $\begin{array}{l}\text { Morning darkness } \\
(06: 23)\end{array}$ & $\begin{array}{l}\text { Full morning } \\
\text { sunlight (08:29) }\end{array}$ & Midday (12:23) & Dusk (16:46) \\
\hline
\end{tabular}

Figure 5. Visibility of the projected lights on the platform in differing levels of daylight.

As part of the assessment of how passengers respond to the lighting, staff reported in interviews before the introduction of the lighting that the main problems on the platform related to crowding and passengers not knowing where to stand. Various features in the station environment appear to influence where people might stand whilst awaiting the train. The observations indicated that some passengers seemed to be familiar and would greet one another and stand in small clusters. Some would stand adjacent to benches, especially if they had bags or a bicycle. Others appeared to locate themselves near the support posts for the station canopy. Passengers were also observed to be engaged in various activities (e.g., walking along the platform, using their phones, carrying hot drinks or eating), which could influence their responses to any visual cues. These observational findings are corroborated by responses to the 
questionnaire, where survey participants were asked to identify up to three things that might influence where they stood on the platform. Their responses were categorised into five major factors (Presence of other people - seeking quieter areas or where there are friends; Weatherrelated factors - rain and cold; Train and boarding related factors - anticipating the location of train doors, uncertainty over train configuration; Environmental factors - need for good lighting for a task or personal safety; Information related factors - near to information screens).

Analysis of the observational data from the arrival of twenty trains (i.e., at one train door in view of the camera) gives an understanding of the response of people to the lighting in this platform context. There were 15 instances where people appeared to react to the lights (based on observations of 102 people present in the images at the times of analysis). These reactions have been classified into five categories (Table 3).

Table 3. Classification of reactions to the projected light

Type of reaction
$\begin{aligned} & \text { Non-reaction with } \\ & \text { limited possibility } \\ & \text { of noticing }\end{aligned}$
$\begin{aligned} & \text { Non-reaction with } \\ & \text { strong possibility } \\ & \text { of noticing }\end{aligned}$
$\ldots$




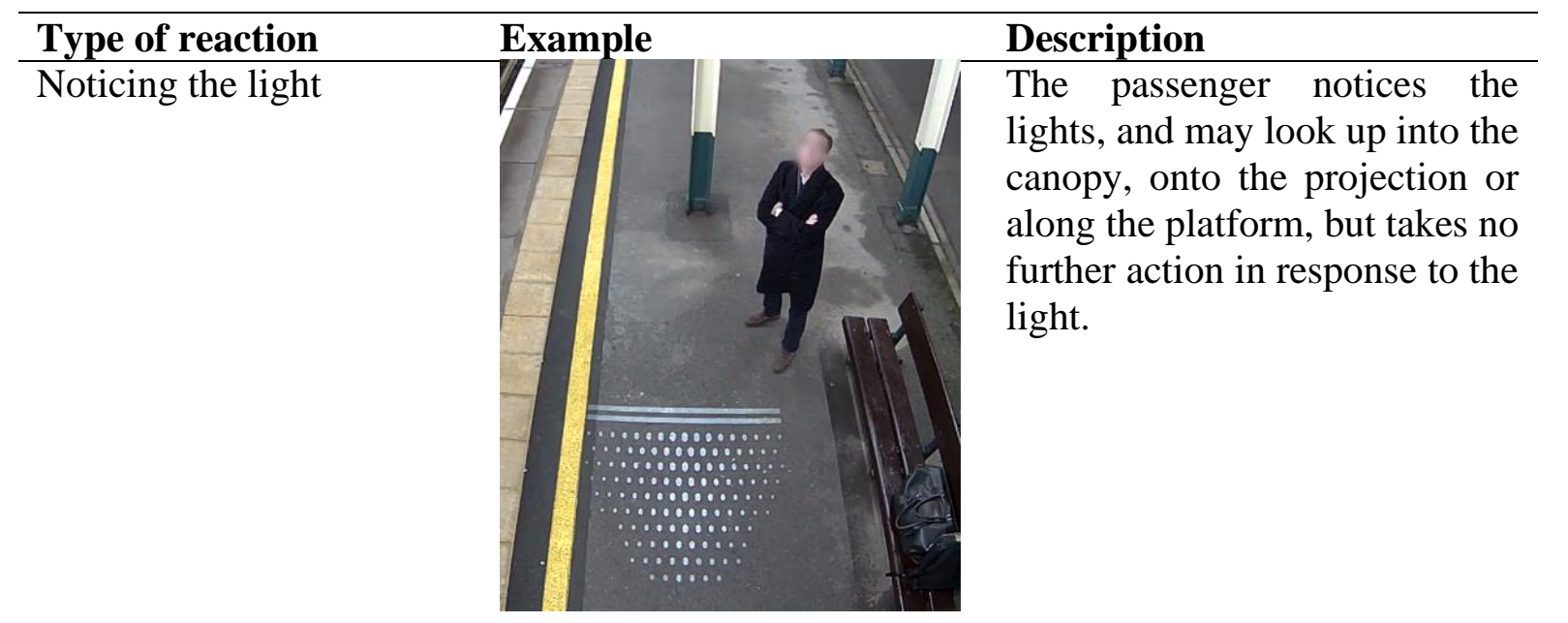

Noticing the light and interacting with the projection

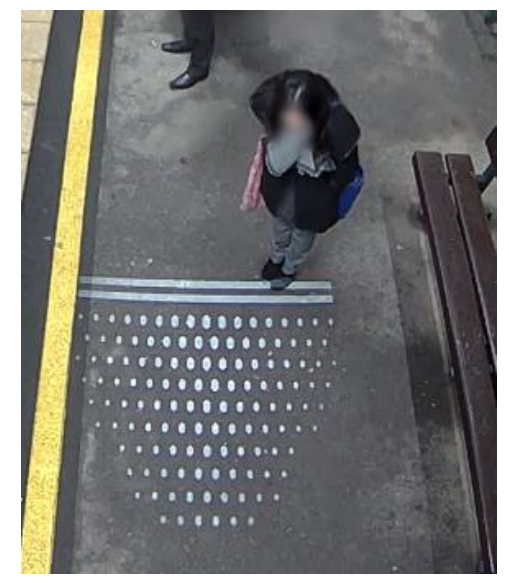

The passenger notices the light and interacts with it by moving a body part (e.g., foot) or whole body into and/or out of the projection.

Noticing the light

and moving

position

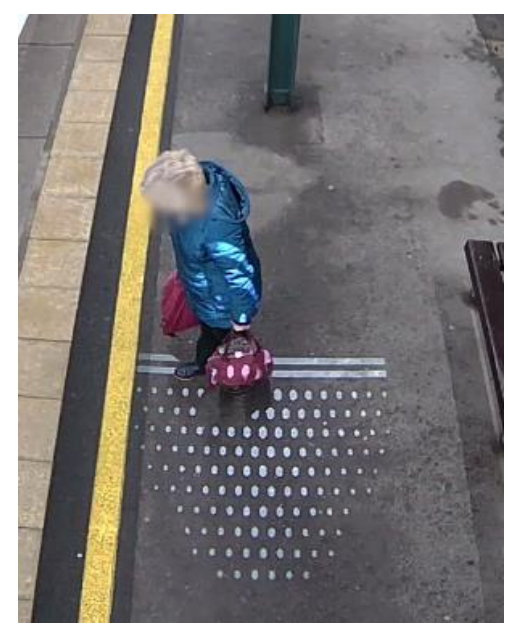

The passenger is positioned outside of the projection area before the light is activated, but moves close to the light after the light is activated.

The findings from observations indicate that a modest proportion of people noticed the lights and a proportion of these were seen to move towards the lights before or during the arrival of a train. The most common reaction noted during the in-person and video observations was to look up into the canopy and around the vicinity and then continue with their previous activity, though some were seen to interact with or take up a position on or close to the projection. These observations are consistent with findings from interviews with station staff 
who had noticed passengers responding to the lights. One staff member estimated that about $10 \%$ of passengers seemed to be reacting to the lights, and another suggested that he had noticed people moving to stand on the projected image, though could not be sure whether this just a coincidence.

Whilst only a small number of passengers have been observed to respond in an optimal way to the lights, a serendipitous finding during a site visit is helpful in appreciating how a small initial effect might have a larger effect on the efficiency of boarding behaviours. During the collection of demonstration photographs of the lighting, an actor boarding a train moved into the target location, as indicated by the projected lighting. Images in Figure 6 show the actor moving into position and other members of the public (otherwise unprompted), taking up positions behind the actor and awaiting the appropriate moment to board the train after passengers had alighted.
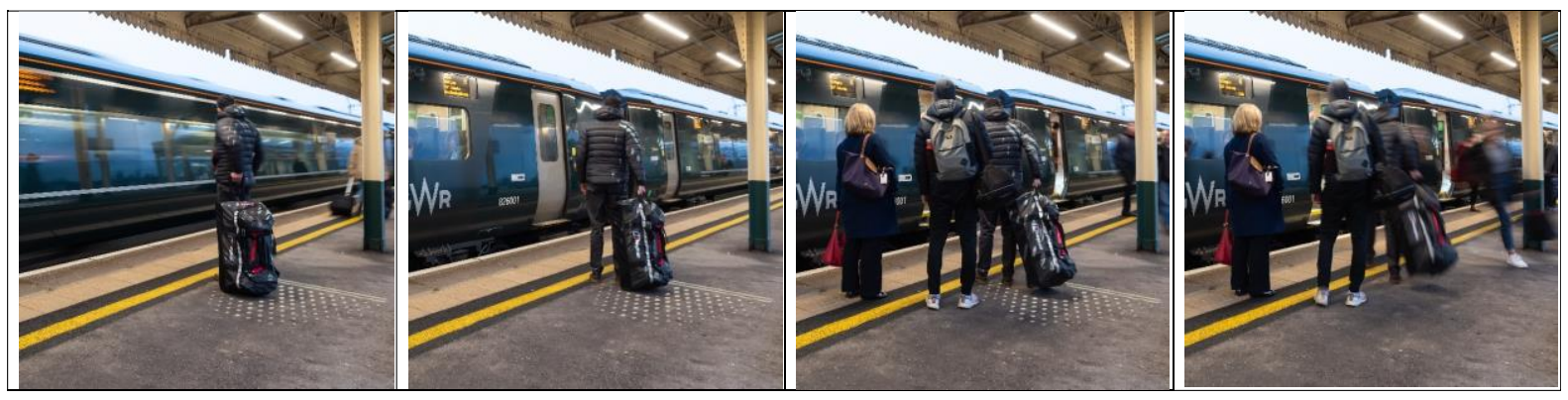

Figure 6. Sequence of photographs showing queuing behaviour at the platform light.

Findings from the survey give an indication of whether passengers appreciate the lighting. The survey participants stated that they had noticed the lighting, with nine out of 11 describing this as visible or very visible. Five of the 11 were able to give plausible explanations of the purpose of the lighting, recognising that this related to the location of the train doors, but some were not convinced that this was indicated accurately. Generally, passengers were not sure whether the lights would be helpful in assisting them to find where to stand on the platform. The survey responses suggest that those responding did not understand the intended meaning that is conveyed by the projected lights, and this may have limited how many people changed their behaviour in response to the lighting cues. It is possible that passengers may not feel the need to respond to the lighting cue in the situation that was tested at this station. Due to low levels of crowding, there may be a limited advantage to standing in a particular location to await the train. 


\subsection{Findings from the study of handrail lighting on the stairway}

It was not possible to count in real time the total number of people observed using the staircase during the observation periods. 334 movement paths of passengers were observed in samples before (144 passengers) and after implementation of the lighting (190 passengers). Eight passengers completed questionnaires during the pre-intervention period and seven during the post-intervention trial period (ages within groups from 18-24 through to 65-74, 10 male:4 female and all used the staircase on all or some visits to the station). Four members of station staff were interviewed prior to installation of the lights and two afterwards.

When assessing the functioning of the lighting, the lights were most visible during the hours of darkness, as indicated in Figure 7. The movement of the blue lights on the handrail was most noticeable around sunrise as it reflected on the surface behind the handrail. Before this time, the movement effect could be masked by the general brightness of other station lights. In daylight conditions, the handrail lights were less obvious, though still visible. In responses to the questionnaire, six of the seven participants said that they had noticed the lights, with four of these rating these as visible or very visible on a scale.

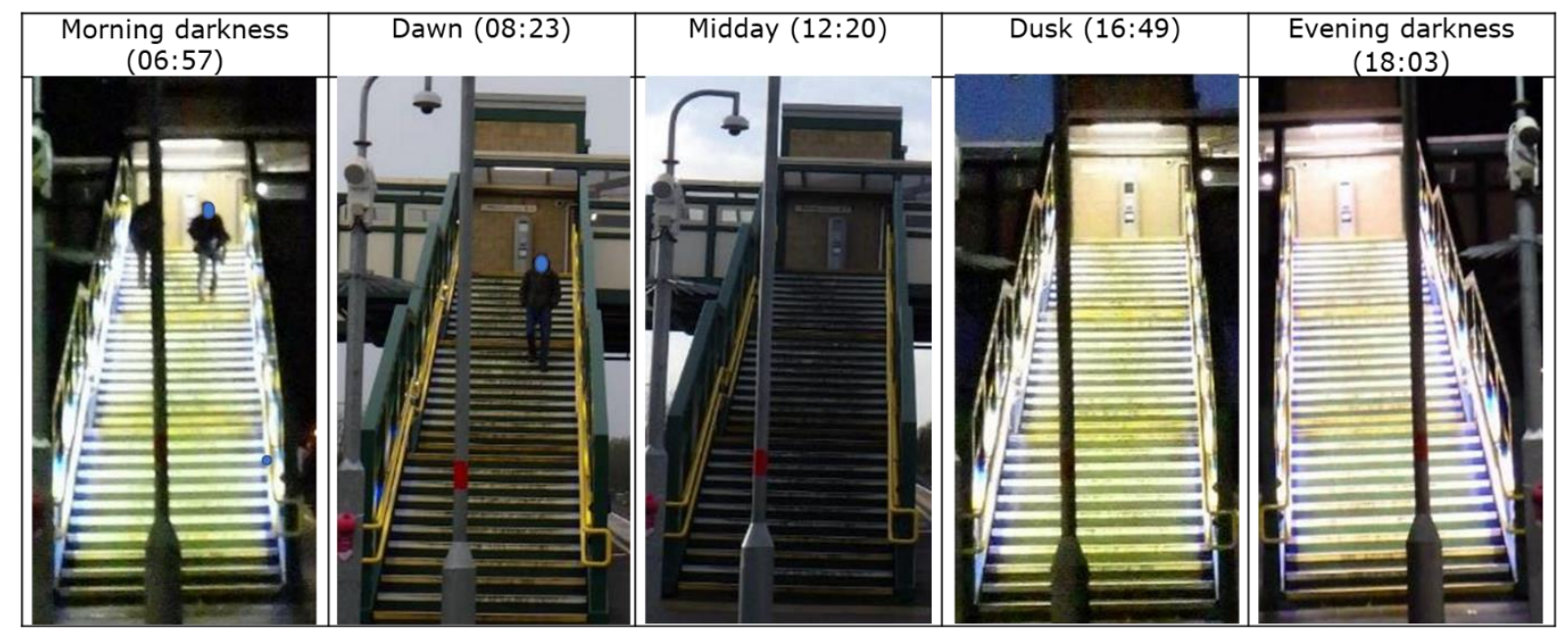

Figure 7. Visibility of the stairway lights in differing levels of daylight.

Analysis of the observational data was used to determine whether passengers move up and down on the appropriate side of the stairway. 720 observations of location were recorded for the movements of the 144 passengers before the introduction of the lighting (i.e., noting their lateral location in each of the five horizontal sections). Frequencies were noted for the number of times people used a particular zone, and percentages were calculated for each zone and then rounded to the nearest integer. These findings are displayed in Figure 8, using the 
depth of shading to represent the occupation of the zones as passengers were descending and ascending. The figure also shows the corresponding findings for observations that were carried out after introduction of the lights, based on the movements of 190 passengers, producing 950 position observations.

Inspection of the figure reveals that before the lights were introduced, movements paths were largely along the left side of the stairs whilst ascending (descriptions of left and right are as in the direction of travel on the stairs) and largely along the left and centre when descending. There were a small number of lateral movements to the right, near the bottom of the staircase, possibly due to other users' presence. After introduction of the lights, the use of the left hand side for descending is greater and there is a shift from the centre to the opposite side of the staircase. For ascending, there is an increase in the proportion of passengers using the right hand side. This was not the effect that was expected from this configuration of lighting, chasing upwards on the left hand side and downwards on the right (as viewed from the bottom in Figure 8). These findings may have been influenced by the limitations in visibility of the movement effect at some times of the day.

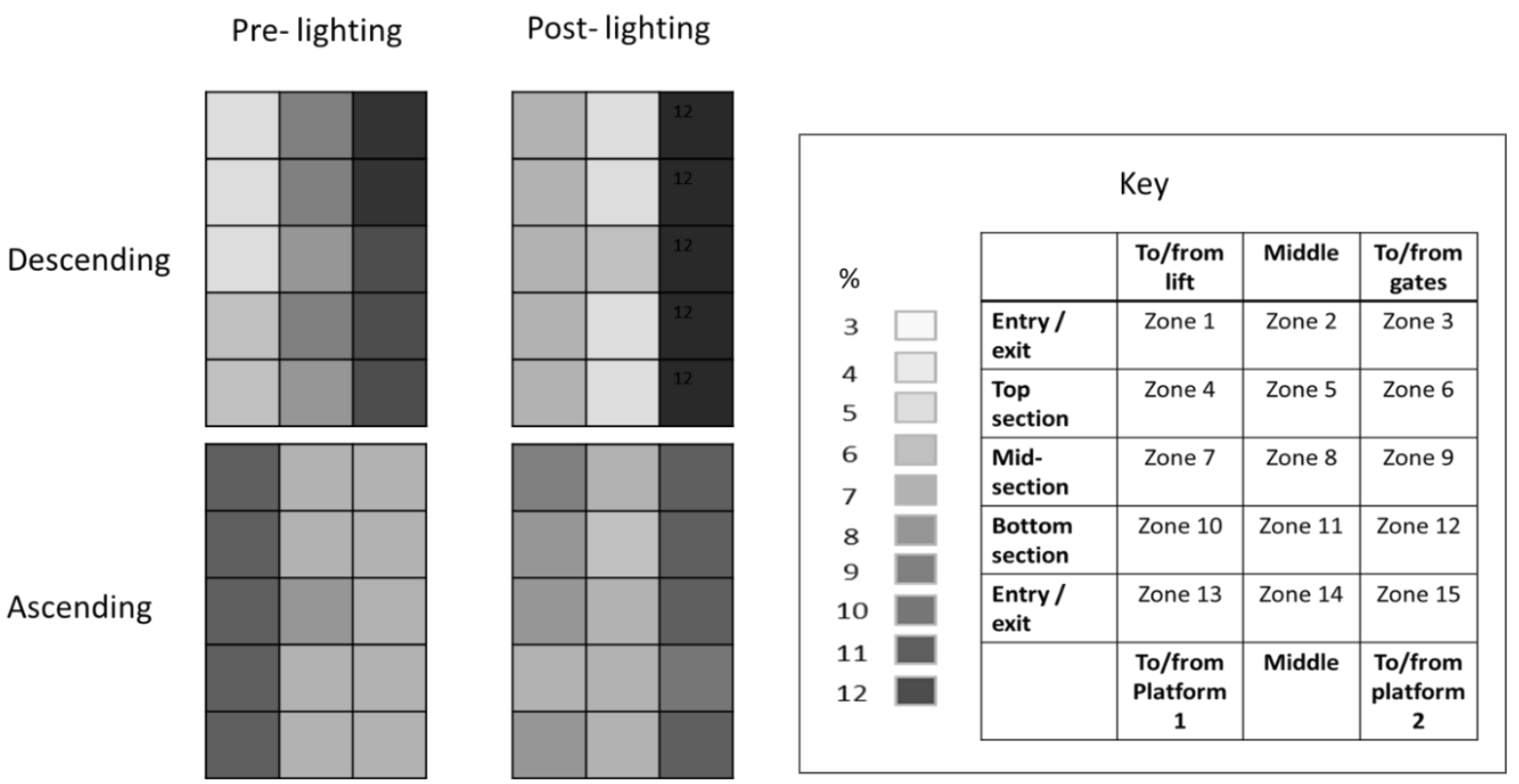

Figure 8. Comparison of the occupation of the zones on the stairs before and after the lighting intervention, whilst ascending and descending (expressed as a percentage of people observed).

Several people were observed to notice and attempt to interact with the lights in similar ways to those classified in the study of projected platform lighting. Three response types have been identified: looking more closely at the lights as people moved through the staircase; 
stopping to examine the lights; and of particular interest in this study, changing pathways after noticing the lights. These behaviours were not noted in the pre-installation observations, so they are likely to be new behaviours in response to the lights.

It is possible that the ability to see the lighting in the handrail may have been restricted for passengers at some levels of crowding. It was also difficult to observe the reactions of the people on the stairway when it was busy. As a result, no counts of the frequencies of responses have been attempted.

In each of the surveys (before and after the introduction of the lights) almost all of the participants stated that they "keep to the left", with several saying this was a generally accepted rule or that it felt natural to do so. Other reasons given for the choice of sides included the need to hold the handrail with a preferred hand (one right hand and two left hand) or because they were influenced by their entry point to the staircase or by the particular platform that they needed at the bottom of the stairs. Two participants referred to choosing a side of the stairway to ensure that their movements aligned with others. The participants did not explicitly refer to any potential influence of the lights in the open questions within the survey.

Staff responses indicated that passengers did not always use the preferred left side of the stairway, but their doing so does not cause any problems at the station. When questioned, the staff members could not report any changes that they had observed in passenger behaviours since the lights had been installed.

The passenger survey and staff interview findings were used in determining whether passengers appreciated the stairway light and whether this improved their experience of using the station. Prior to the introduction of the lighting, the passengers responding to the survey did not feel strongly positive or negative about their experience of the stairway (3/8 satisfied with their experience of using the stairway; $5 / 8$ neither satisfied nor dissatisfied). After introduction of the lighting, there seemed to be a more positive response to this question (1/7 very satisfied, 4/7 satisfied, 2/7 neither satisfied nor dissatisfied), though it is worth emphasising that this is based on a very small sample of respondents. The purpose of the lighting was not commonly recognised by those responding. Two correctly suggested it was to influence "keeping left" or indicating the side of the staircase for ascending and descending. One referred to it influencing the speed of movement, though expressed caution about introducing safety risks by encouraging rushing. Ratings of the lighting intervention were generally positive (4 liked it or liked it a lot; 2 either did not like it or did not like it at all).

Two of the staff who were interviewed prior to introduction of the lighting were very positive about the proposed lighting, particularly on the staircase, reasoning that the lights 
would encourage passengers to make their own decisions regarding safety and efficiency of movement at the station. One of the staff members who was interviewed after operation of the lights provided a valuable perspective on how passenger responses may develop over time, with the lights helping to break established habits. They also commented on how the lighting could reinforce staff instructions (i.e., to keep to the left and hold the handrail).

\section{Discussion}

This study has introduced and carried out initial evaluations of two new lighting interventions in an operational railway setting, attempting to tackle problems that have been identified by industry staff..$^{5}$ This is an important achievement as there is an absence of good evaluation studies in most industrial contexts and academic publications. ${ }^{7}$ A rigorous process of evaluation has been developed (adapted from ${ }^{11}$ ) and applied, collecting observational data and reports from those using or supervising these locations. This contributes to an understanding of the railway context, identifying how people behave and interact with their surroundings and determining whether, how and why the lighting interventions work in the current circumstances. $^{7,24}$

It is clear that the lights have been noticed and initiated responses from a number of passengers (section 5.1). These immediate, small scale responses cannot enable conclusions to be drawn on whether or not the lights work in managing passenger flows and safety around the station, but they do provide the justification for further studies into these behavioural responses, examining these over longer periods. The evaluation approach provides an understanding of the method and associated research tools for a larger scale programme of research, recognising the challenges for such field-based lighting studies in operational settings (section 5.2). There are features of the study environment that may not have drawn out the full potential of the lighting interventions. Suggestions for development of the products and guidance for further evaluation are provided (section 5.3).

\subsection{First results from the field tests}

The evaluations of the projected platform lighting and the handrail lighting on the staircase have each shown that these lighting innovations can attract responses from passengers in real world locations. Five observable responses were identified in the study of the projected platform lighting (Table 3). This classification can be verified in more extensive trials of behavioural responses to lighting, including examination of inter-observer reliability in coding 
observations $^{25}$ and collecting more statistics on the frequencies of the responses with larger numbers of passengers over extended time periods.

The numbers of observable responses were modest, though a small number of responses may be sufficient to influence more ordered boarding behaviours and movements around the station. In the study by Corbetta et al. ${ }^{26}$ only a small percentage of people being influenced by arrow like lighting stimuli resulted in greater numbers (almost a third of people) following the directed path given by the lighting cue. Influencing a few people directly using the lighting may be sufficient for other people to follow the cue from the informed passenger. This effect was also observed in the serendipitous findings on the platform at the trial site in the current study (Figure 6).

There were also indications that the lights on the staircase influenced a small number of people to change their lateral positioning on the staircase, moving towards the handrails at the left or right of the staircase. This was not always the desired outcome (i.e., with some moving to the right rather than the left), suggesting a limited response to the movement of the lighting in the conditions of this study. However, the observed response of passengers, placing them closer to a handrail than walking down the centre, might contribute to safer stairway usage. ${ }^{27}$ This response was again rather modest, but the effect could be multiplied in various circumstances: if the leading person forms a channel of movement, ${ }^{28}$ followed by others ${ }^{29}$ through a crowd; or where the lighting reinforces the staff instructions to keep left, influencing social norms ${ }^{30}$ and producing a change in behaviour over time.

\subsection{Challenges for field-based lighting studies in this type of setting}

Evaluating lighting interventions in operational environments is important to appreciate how these can influence behavioural responses. What has been achieved so far is more than is typically done to evaluate many new interventions. Various challenges have been encountered in relation to implementation and evaluation of the interventions.

In some settings, especially railways, innovation is difficult, ${ }^{31}$ in part due to conservative attitudes to safety risk. Even with very strong support from stakeholders within the industry, there were problems securing permission for study at anything beyond a small and low risk station, without the numbers of passengers and shorter dwell times ${ }^{6}$ that increase the pressure on passengers, as can be seen at some of the larger stations. This meant that the conditions may not have fully tested features of the lighting interventions. People are likely to react differently to the lighting interventions at crowded locations, where they have more 
incentives to take up an early position at a desirable waiting location or follow a particular path for ease of movement.

Whilst this was not the ideal station, it is important to take the opportunities that arise for studies in real-world settings, to understand how wide-ranging individual, location and railsystem related factors and variability in this type of setting can impact the planning and execution of this type of study. The individual factors include the actual behaviours and activities $^{32}$ of passengers in a variety of contexts that can emerge in field trials, such as their waiting behaviours or the way that some would walk alongside the train as it draws to a stop, rather than stand in a chosen location. Location-related factors include the differences that are introduced by layouts and configurations of the platforms and related infrastructure, causing a predominance of entry or exit to one side of a staircase. Rail system-related factors include the impacts of timetabling and peak train times, which are desirable to study greater numbers of people but could result in oversampling of commuters and emphasise a weakness in the lighting to influence habitual behaviours. Finally, examples of variability could be seen in the differences in numbers of people on platforms or stairways for different train arrivals, or the small variations in how trains align with points on the platform, which may have impacted how some people perceived the usefulness of the (fixed) projected lighting. The descriptive detail that has been collected from this initial study has demonstrated that the lighting interventions need to compete with many situational factors that can influence behavioural responses.

Protracted negotiations for various permissions (section 3.2) introduced significant delay in completing the installation of the lighting products. They had subsequent impacts on the time available for evaluation activities (something that is not uncommon in studies where other elements of a project overrun, limiting the time for extensive evaluation studies). Consequently, the study was carried out over a short period of time, very soon after the fitting and first operation of the lighting, when many passengers were experiencing the lights for the first time. This may have influenced their understanding of the purpose of the lights and provided limited opportunities to witness adaptation in behaviours or incidental learning effects $^{33}$ from longer exposure to the new lighting technologies.

The ability to compromise and adapt the research approach ${ }^{15}$ were important to achieving a successful outcome. At this stage of testing, it was not possible to anticipate the range of factors with the potential to influence the study, the reactions of passengers to the lighting or their willingness to participate in the survey (either in the short time periods that they were present on the platform or in response to the alternative arrangements to access the online survey). Nevertheless, there are many opportunities for the researcher to assimilate 
knowledge in this type of study in an operational setting, through formal and informal observations and through talking to many people and learning from them. This has to occur within the structure provided by the intended research design and the associated ethical approvals, but these must be flexible enough for the researcher to adapt in order to understand the reality of the situation that is being observed..$^{34}$

\subsection{Recommendations for future development and evaluation}

There is potential to improve the responses to the lighting through the development of the design of the lighting interventions. In this first evaluation of projected platform lighting the lighting cue was intended to be a simple, intuitive indicator of a desirable location to await the train, without adding to the visual clutter that is evident from an array of signage in this type of station environment. ${ }^{3,4}$ The initial evidence suggests that many people did not understand the cue from the lighting, and the design may be too abstract. Future trials could provide a more meaningful graphic (e.g., a carriage number or a suitable icon to indicate that this is the intended place to wait for the train), accompanied by colour changes or different lighting effects to attract attention. Exploring the movement cue from the stair lighting in different levels of background illumination and varying movement speed for the handrail lighting could test capability to influence choice of route on the stairway and speed up or slow down passenger movements. These studies could be supported with the provision of more information for passengers, though there is still value in pursuing a solution that initiates an intuitive response. The practicalities of engaging effectively with the passengers to collect survey data during time constraints of travel need further consideration in future work.

With the existing use of IoT technologies in the products and the development of sensing technologies ${ }^{35}$ within this type of setting to improve understanding of distributions of passengers along platforms ${ }^{36}$ and staircases, it may be possible to examine influencing features of the lighting on a larger scale at a busier station. Lighting cues could also be adapted to respond in an active and appropriate way to the numbers and behaviours of people in a location. Dynamic, rather than fixed projectors, could be considered to adjust projections to the actual location of a train as it stops at a station and enable selective operation of projectors to align with doors for different train types, lengths and levels of occupancy.

Visibility of both lighting interventions was a concern when there were greater levels of background illumination. It may be possible to solve this by increasing the illumination of the light sources. There are also likely to be many other interior applications of these types of 
lighting cues, where there is value in influencing the behaviours and movement patterns of people in rail (underground, metro) or other transport, city and entertainment locations.

As a concluding thought, very few people would have predicted how things have changed on a global scale in the space of a few months. This study was completed at the end of January 2020 in Great Britain, when there were only emerging indications of problems arising from the Covid-19 global pandemic. These lighting interventions were tested for their abilities to support congregation and efficiency of movements of people in crowds, and it is likely that there will be future applications of the lighting for this purpose. It is also possible that in new manifestations of the designs, the lighting products could have legitimate uses in managing of crowding or spacing of people or groups, as required by concepts such as social distancing (e.g., giving guidance for separation distances, preferred walking routes, one way routes).

\section{Conclusions}

The lighting interventions on the platform and stairway were noticed and initiated responses from passengers, though it is difficult at this stage to comment on the long term impact of the lighting to improve the efficiency of passenger movements around stations. This is a valuable study, establishing important details of the station context, passenger behaviours and a method for evaluation of such lighting interventions. Recommendations have been made for additional areas of study, particularly that repeating and extending aspects of the evaluation study would be beneficial after a period of several months, in order to establish learned effects of the lighting.

By taking this exploratory approach to the evaluation, it has been possible to determine how these lighting interventions operate in practice, to discover not just how they work but also why they do not always work in the way that was envisaged at the outset. It is apparent that there are many situational factors (individual, location and rail system-related factors) that could compete with the lighting and introduce variability in behavioural responses. There is value in pursuing the study of the behaviour influencing characteristics of light in this type of setting, developing an understanding of the context and changing circumstances in the real world settings into which they are implemented. The findings from the current study provide insights and guidance for designers, developers and operational staff within railways and also other transport/service-related industries where managing or influencing the movements of people movement is important. 


\section{Acknowledgements}

The authors disclosed receipt of the following financial support for the research, authorship, and/or publication of this article: This work was supported by a grant from Innovate UK in the UK [grant number 103965].

\section{Declaration of Conflicting Interests}

Authors AG and NP are employed by DW Windsor and have a financial interest in lighting products which may be developed based on the work described in this paper.

\section{References}

1. Ajzen I and Madden TJ. Prediction of Goal-Directed Behavior: Attitudes, Intentions, and Perceived Behavioral Control. Journal of Experimental Social Psychology 1986; 22: 453-474.

2. Edwards B. The modern station: new approaches to railway architecture. London: Taylor \& Francis. 2013.

3. Pattison M, Wilson JR and Clarke T. Wayfinding, Accessibility, Inclusive Design and Passenger Information Systems:'Euston Station and Beyond'. In People and Rail Systems. CRC Press, 2016, pp 49-60.

4. Boersema T, Zwaga HJG and Adams AS. Conspicuity in realistic scenes: an eyemovement measure. Applied Ergonomics 1989; 20(4): 267-273.

5. Hughes N, Ryan B, Hallewell M, Coad N, Grant A, Parrott N and Thompson K. Identifying new concepts for innovative lighting-based interventions to influence movement and behaviours in train stations. Lighting Research \& Technology in press; https://doi-org.ezproxy.nottingham.ac.uk/10.1177/1477153520904405.

6. Cornet S, Buisson C, Ramond F, Bouvarel P and Rodriguez J. Methods for quantitative assessment of passenger flow influence on train dwell time in dense traffic areas. Transportation Research Part C: Emerging Technologies 2019; 106: 345-359.

7. Neumann WP, Eklund J, Hansson B and Lindbeck L. Effect Assessment in Work Environment Interventions: A Methodological Reflection. Ergonomics 2010; 53(1): 130-137.

8. Nilsen P. The How and Why of Community Based Injury Prevention. A Conceptual and Evaluation Model. Safety Science 2007; 45: 501-521.

9. Pawson T, Greenhalgh T, Harvey G and Walshe K. Realist Review: A New Method of Systematic Review Designed for Complex Policy Interventions. Journal of Health Services Research and Policy 2005; 10 (Suppl 1): 21-34.

10. Pederson LM, Nielsen KJ and Kines P. Realistic Evaluation as a New Way to Design and Evaluate Occupational Safety Interventions. Safety Science 2012; 50: 48-54.

11. Hills D and Junge K. Guidance For Transport Impact Evaluations. The Tavistock Institute, London, 2010.

12. Cosma G, Ronchi E and Nilsson D. Way-finding lighting systems for rail tunnel evacuation: A virtual reality experiment with Oculus Rift ${ }^{\circledR}$. Journal of Transportation Safety \& Security 2016; 8: 101-117.

13. Pedersen E and Johansson M. Dynamic pedestrian lighting: Effects on walking speed, 
legibility and environmental perception. Lighting Research and Technology 2018; 50: 522-536.

14. Ronchi E, Nilsson D, Kojic' S, Eriksson J, Lovreglio R, Modig H and Walter AL. A virtual reality experiment on flashing lights at emergency exit portals for road tunnel evacuation. Fire Technology 2016; 52: 623-647.

15. Ryan. B. Accounting for differing perspectives and values: the rail industry. In Human and Organisational Factors 2020 (pp. 5-13). Springer, Cham.

16. Kletz T. Hazop — past and future. Reliability Engineering \& System Safety 1997; 55: 263-266.

17. Fujiyama $\mathrm{T}$ and Tyler N. Prediction the walking speed of pedestrians on stairs. Transportation Planning and Technology 2010; 33(2): 177-202.

18. Liu MW, Wang SM, Oeda Y and Sumi TN. Simulating uni- and bi-directional pedestrian movement on stairs by considering specifications of personal space. Accident Analysis \& Prevention 2019; 122: 350-364.

19. Kretz T, Grünebohm A, Kessel A, Klüpfel H, Meyer-König T and Schreckenberg M.. Upstairs walking speed distributions on a long stairway. Safety Science 2008; 46(1): 72-78.

20. Norén J, Delin M and Fridolf K. Ascending Stair Evacuation: What do We Know? Transportation Research Procedia 2014; 2: 774-782.

21. Kuligowski E, Peacock R, Reneke P, Wiess E, Hagwood C, Overholt K, Elkin R, Averill J, Ronchi E, Hoskins B and Spearpoint M. Movement on Stairs During Building Evacuations, NIST Technical Note 1839, National Institute of Standards and Technology, 2015.

22. Hsieh HF and Shannon SE. Three approaches to qualitative content analysis. Qualitative Health Research, 2005; 15(9): 1277-1288.

23. O'Caithan A, Murphy E., Nicholk J. Three techniques for integrating data in mixed methods studies. British Medical Journal 2010; 341:c4587.

24. Ryan B, Kallberg V-P, Rådbo H, Havârneanu GM, Silla A, Lukaschek K, Burkhardt JM, Bruyelle J-L, El-Koursi E-M and Beurskens E. Collecting evidence from distributed sources to evaluate railway suicide and trespass prevention measures. Ergonomics 2018; 61: 1-21.

25. Olsen, N.S. Reliability studies of incident coding systems in high hazard industries: A narrative review of study methodology. Applied Ergonomics 2013; 44(2): 175-184.

26. Corbetta A, Kroneman W, Donners M, Haans A, Ross P, Trouwborst M, Van de Wijdeven S, Hultermans M, Sekulovski D and van der Heijden F. A large-scale reallife crowd steering experiment via arrow-like stimuli. 9th International Conference on Pedestrian and Evacuation Dynamics. Lund, Sweden 2018.

27. Jackson $P$ and Cohen HJ. An in-depth investigation of 40 stairway accidents and the stair safety literature. Journal of Safety Research 1995; 26(3): 151-159.

28. Kok VJ, Lim MK and Chan CS. Crowd behavior analysis: A review where physics meets biology. Neurocomputing 2016; 177: 342-362.

29. Pan X, Han CS, Dauber K and Law KH. A multi-agent based framework for the simulation of human and social behaviors during emergency evacuations. AI \& Society 2007; 22(2): 113-132.

30. Ajzen I and Madden TJ. Prediction of Goal-Directed Behavior: Attitudes, Intentions, and Perceived Behavioral Control. Journal of Experimental Social Psychology 1986; 22: 453-474.

31. Palacin R, Golightly D, Ramdas V and Dadashi N. Evaluating the impact of rail research: Principles to maximise innovation uptake. Proceedings of the Institution of 
Mechanical Engineers, Part F: Journal of Rail and Rapid Transit 2016; 230 (7): 1673 1686.

32. Daniellou F. The French-speaking ergonomists' approach to work activity: crossinfluences of field intervention and conceptual models. Theoretical Issues in Ergonomics Science 2005; 6: 409-427.

33. Greene JA, Copeland DZ, Deekens VM. A model of technology incidental learning effects. Educational Psychology Review 2020: 1-31.

34. Bieder C. The Dual Face of HOF in High-Risk Organizations. In Human and Organisational Factors 2020;pp. 111-116. Springer, Cham.

35. Mora H, Gilart-Iglesias V, Perez-del Hoyo R., Andújar-Montoya MD. Comprehensive System for Monitoring Urban Accessibility in Smart Cities. Sensors 2017; 17: 1834. doi:10.3390/s17081834.

36. Oliveira LCR, Fox C, Birrell S and Cain R, Analysing passengers' behaviours when boarding trains to improve rail infrastructure and technology. Robotics and ComputerIntegrated Manufacturing 2019; 57: 282-291. 